RESEARCH REPORT

\title{
Psychological distress, physical illness, and risk of coronary heart disease
}

\author{
F Rasul, S A Stansfeld, C L Hart, G Davey Smith
}

J Epidemiol Community Health 2005;59:140-145. doi: 10.1136/jech.2004.019786

See end of article for authors' affiliations

.....................

Correspondence to: Mr F Rasul, Department of Psychiatry, Institute of Community Health Sciences, Barts and the London School of Medicine and Dentistry, Queen Mary, University of London, Mile End Road, London El 4NS, UK; F.R.Rasul@qmul.ac.uk

Accepted for publication 2 June 2004
Study objective: The aims of this study are to confirm the association between psychological distress and coronary heart disease (CHD) using an epidemiological community study with hospital admissions data and to examine if any association is explained by existing illness.

Design: Prospective cohort study modelling the association between psychological distress, measured using the 30 item general health questionnaire (GHQ), and hospital admissions data for CHD (ICD 410414), using proportional hazards modelling adjusted for sociodemographic, CHD risk factors, and angina, bronchitis, diabetes, ischaemia, and stroke.

Setting: Two suburbs of Glasgow, Renfrew and Paisley, in Scotland.

Participants: 6575 men and women aged 45-64 years from Paisley.

Main results: Five year CHD risk in distressed men compared with non-distressed men was $1.78195 \%$ confidence intervals (Cl), 1.15 to 2.75$)$ in age adjusted analysis, $1.78(95 \% \mathrm{Cl}, 1.14$ to 2.79$)$ with sociodemographic and CHD risk factor adjustment, and 1.61 (95\% Cl 1.02 to 2.55) with additional adjustment for existing illness. Psychological distress was unrelated to five year CHD risk in women. In further analysis, compared with healthy, non-distressed men, distressed physically ill men had a greater risk of CHD than non-distressed physically ill men, a relative risk of 4.01 (95\% $\mathrm{Cl} 2.42$ to 6.66 ) compared with 2.12 (95\% Cl 1.35 to 3.32$)$.

Conclusion: The association of psychological distress with an increased risk of five year CHD risk in men could be a function of baseline physical illness but an effect independent of physical illness cannot be ruled out. Its presence among physically ill men greatly increases CHD risk.
C oronary heart disease (CHD) risk factors do not entirely explain the risk of CHD events. ${ }^{12}$ This has led to an examination of other putative CHD risk factors. Literature reviews have identified psychological distress, specifically depressive disorder, to be a significant and consistent predictor of CHD. ${ }^{3-11}$

Many studies have showed that psychological distress is associated with increased risk of CHD. ${ }^{12-19}$ Psychological distress was associated with up to threefold increased risk of CHD in men that was sustained even after adjustment for CHD risk factors and other confounders. ${ }^{1}{ }^{12} 20$

However, the nature of psychological distress is unclear. It may be that psychological distress reflects some underlying, chronic illness that influences CHD risk, or that psychological distress is indicative of depressive illness that still confers risk in the absence of any underlying chronic condition. The nature of psychological distress was examined in the NHANES study. ${ }^{21}$ Hopelessness, which correlated moderately with depression, was associated with an increased CHD risk in a dose dependent way even after adjustment for sociodemographic, CHD risk factors, and self reported health at baseline. Similarly, in the New Haven EPESE study ${ }^{17}$ psychological distress was associated with incident CHD but only among women without impairment in physical functioning. While these studies suggest psychological distress as an independent predictor of CHD, further studies are required to understand the pathways between psychological distress, physical health, and CHD.

The aim of this study was to examine the association between psychological distress and CHD in men and women, hypothesising increased CHD risk in psychologically distressed compared with non-distressed respondents and to examine the influence of physical ill health in this association.

\section{METHODS}

The study population and instruments used in the initial clinical screening examination have been described previously. ${ }^{22}$ Appropriate local research ethics committees approved the study protocol.

\section{Sample}

At baseline (1972-76) a total of 7052 men and 8354 women aged 45-64 took part in the study. Mortality in this cohort was tracked by the NHS central registry in Edinburgh (Scotland). Morbidity records relating to all hospitalisations for cohort members were collected by the information and statistics division of NHS Scotland. There was an $80 \%$ overall response rate.

\section{Measurement of psychological distress}

Psychological distress was measured using the 30 item GHQ. ${ }^{24}$ The GHQ is a well established screening questionnaire for non-psychotic psychological distress. After the screening phase of the survey had been underway in Paisley for seven months, the GHQ was introduced to measure psychological distress in the Paisley sample. Thus, early participants in Paisley did not complete the GHQ. At baseline, GHQ data were collected from 8465 men and women, with a response rate of $99.8 \%$ of sample offered the GHQ. At baseline a threshold of 3/4 on the 30 item GHQ was selected to denote possible psychiatric caseness. Respondents scoring on 4 or more questions were considered to be cases. This threshold was based on the results of a validation study, which involved some participants from this study, carried out as a prelude to the MRC mild hypertension study. ${ }^{25}$

Abbreviations: $C H D$, coronary heart disease; $G H Q$, general health questionnaire 
Table 1 Sample baseline characteristics of GHQ negative and positive men and women

\begin{tabular}{|c|c|c|c|c|}
\hline$(n=6575)$ & $\begin{array}{l}\text { GHQ negative men } \\
\text { Number (\%) }\end{array}$ & $\begin{array}{l}\text { GHQ positive men } \\
\text { Number (\%) }\end{array}$ & $\begin{array}{l}\text { GHQ negative women } \\
\text { Number (\%) }\end{array}$ & $\begin{array}{l}\text { GHQ positive women } \\
\text { Number (\%) }\end{array}$ \\
\hline Psychologically distressed & $2526(86)$ & 405 (14) & $2926(80)$ & $718(20)^{* *}$ \\
\hline CHD at five years & $89(3.5)$ & $26(6.5)^{* *}$ & $24(0.9)$ & $9(1.2)$ \\
\hline No CHD at five years & $2437(96.5)$ & $377(93.5)$ & $2904(99.1)$ & 709 (98.7) \\
\hline Age mean (SD) & $54(6)$ & $54(6)$ & $55(5)$ & $54(6)^{\star *}$ \\
\hline Cigarettes/day & 17 (12) & 18 (12) & $8(9)$ & $10(10)^{\star *}$ \\
\hline \multicolumn{5}{|l|}{ Social class $n(\%)$} \\
\hline 1 & $169(7)$ & $26(6)^{*}$ & $91(3)$ & $10(1)^{*}$ \\
\hline$\|$ & 420 (17) & $51(12)$ & $525(18)$ & $122(17)$ \\
\hline IIIN & 312 (12) & $47(12)$ & $798(27)$ & $184(26)$ \\
\hline$\| M$ & 936 (37) & $147(36)$ & $443(15)$ & $108(15)$ \\
\hline IV & $531(21)$ & $95(24)$ & 778 (27) & $201(28)$ \\
\hline V & $158(6)$ & $39(10)$ & $291(10)$ & $93(13)$ \\
\hline \multicolumn{5}{|l|}{ Marital status $n(\%)$} \\
\hline Married & $2232(88)$ & $332(82)^{* *}$ & 2078 (71) & $513(71)$ \\
\hline Widowed & $74(3)$ & $28(7)$ & 387 (13) & $112(16)$ \\
\hline Single & $195(8)$ & $39(10)$ & 400 (14) & $67(9)$ \\
\hline Other & 25 (1) & $6(1)$ & $61(2)$ & $26(4)$ \\
\hline \multicolumn{5}{|l|}{ Mean (SD) of CHD risk factor } \\
\hline Systolic BP, mmol/Hg & $147(21)$ & $146(23)$ & $147(24)$ & $144(24)^{\star *}$ \\
\hline Diastolic BP, mmol/Hg & $85(13)$ & $86(13)$ & $84(13)$ & $83(13)$ \\
\hline Cholesterol, $\mathrm{mmol} / \mathrm{l}$ & $6.0(1.0)$ & $6.0(1.0)$ & $7.0(1)$ & $7.0(1)$ \\
\hline Body mass index $\mathrm{kg} / \mathrm{m}^{2}$ & $26.3(3.4)$ & $25.6(3.5)^{\star}$ & $26.2(3.9)$ & $25.2(4.9)$ \\
\hline Forced expiratory volume $1 \mathrm{sec}$ & $90(22)$ & $85(25)^{\star \star}$ & $93(23)$ & $88(24)^{* *}$ \\
\hline Blood sugar, $\mathrm{mmol} / \mathrm{l}$ & $5(1)$ & $5(1)$ & $5(1)$ & $5(1)$ \\
\hline \multicolumn{5}{|l|}{ Angina $\mathrm{n}(\%)$} \\
\hline No & $2164(86)$ & $262(55)^{\star *}$ & $2586(88)$ & $561(71)^{\star *}$ \\
\hline Yes & $362(14)$ & $143(35)$ & 340 (12) & $207(29)$ \\
\hline \multicolumn{5}{|l|}{ Bronchitis n (\%) } \\
\hline No & 2425 (96) & $343(85)^{\star *}$ & 2853 (97) & $656(91)^{* *}$ \\
\hline Yes & 101 (4) & $62(15)$ & $73(3)$ & $62(9)$ \\
\hline \multicolumn{5}{|l|}{ ECG ischaemia n (\%) } \\
\hline No & 2297 (91) & 359 (89) & $2649(90)$ & $650(90)$ \\
\hline Yes & $229(9)$ & $46(11)$ & $277(10)$ & $68(10)$ \\
\hline \multicolumn{5}{|l|}{ Stroke n (\%) } \\
\hline No & 2500 (99) & $394(97)^{* *}$ & 2908 (99) & $703(98)^{* *}$ \\
\hline Yes & 26 (1) & $11(3)$ & $18(1)$ & $15(2)$ \\
\hline \multicolumn{5}{|l|}{ Diabetes n (\%) } \\
\hline No & 2487 (98) & 401 (99) & $2899(99)$ & 708 (99) \\
\hline Yes & $39(2)$ & $4(1)$ & 27 (1) & 10 (1) \\
\hline
\end{tabular}

\section{Coronary heart disease incidence}

CHD cases after baseline screening were identified from hospitalisation records of first diagnosis code acute admissions and coded on the basis of the International Classification of Disease, Ninth Revision (ICD 9) codes 410-414. After excluding 69 CHD cases that had occurred before baseline screening this yielded 818 CHD cases in the whole cohort. The 0-5 and 5-10 year CHD incidence was defined as those respondents admitted to hospital for CHD for the first time within 1825 and 1826-3650 days of baseline screening. Subsequent admissions for CHD were not counted as one case. The 5-10 year CHD incident cases did not include the 0-5 year CHD incident cases.

\section{Statistical analyses}

The association between baseline variables and GHQ status in men and women was analysed using $\chi^{2}$ tests for categorical variables and age adjusted analysis of variances for continuous variables. The proportional hazards assumption of a constant hazard ratio across follow up time was tested separately for men and women by including an interaction term between psychological distress and log follow up time that was not significant for men $(p=0.14)$ or women $(\mathrm{p}=0.99)$. The associations between psychological distress and 0-5, 5-10 year CHD incidence were analysed using Cox's regression. The first model adjusted for age only, the second for sociodemographic (marital status (married, widowed, single, other) social class (high I, II, IIINM, IIIM IV, V low)) and CHD risk factors (systolic, diastolic blood pressure, smoking, cholesterol, blood sugar, BMI, and $\mathrm{FEV}_{1}$ ), and the third model adjusted for all previous and baseline physical illness (angina, bronchitis, diabetes, ECG ischaemia, and stroke). The interrelation between psychological distress, physical illness, and five year CHD risk in men was assessed in two ways. Firstly, by including a psychological distress, physical illness interaction term in the full model that was not significant $(\mathrm{p}=0.46)$. Secondly, by combining psychological distress and physical illness to create a four category variable (GHQ negative and healthy, GHQ positive but healthy, GHQ negative but ill, GHQ positive and ill). Each category's association with five year CHD risk was assessed in age and fully adjusted analyses. As there were missing data the analyses were on 6575 men and women with complete GHQ and CHD data.

\section{RESULTS}

Table 1 shows the associations between covariates and GHQ caseness. Psychologically distressed women were of lower average age, and smoked more cigarettes on average compared with non-distressed women. Distressed men were more likely to be of lower socioeconomic position, specifically social class IV and V. Distressed women had lower mean SBP and $\mathrm{FEV}_{1}$ values whereas distressed men had lower mean BMI and $\mathrm{FEV}_{1}$ values compared with non-distressed men and women. Psychological distress in men and women was also strongly associated with physical illness, specifically with angina, bronchitis, and stroke (table 1 ).

Table 2 shows the associations between covariates and five year CHD incidence. Five year CHD incidence was associated with age and cigarette smoking in men. Men with incident 
Table 2 Baseline characteristics of men and women who had a CHD event within five years

\begin{tabular}{|c|c|c|c|c|}
\hline \multirow[b]{2}{*}{$(n=6575)$} & \multicolumn{2}{|c|}{ CHD events men } & \multicolumn{2}{|c|}{ CHD events women } \\
\hline & Yes & No & Yes & No \\
\hline Age mean (SD) & $56(5)^{*}$ & $54(5)$ & $57(6)^{*}$ & $55(5)$ \\
\hline Cigarettes/day & $20(12)^{*}$ & 17 (12) & $10(9)$ & $8(9)$ \\
\hline \multicolumn{5}{|l|}{ Social class $n(\%)$} \\
\hline I & $8(7)$ & $169(7)$ & $0(0)^{*}$ & $95(3)$ \\
\hline$\|$ & $23(20)$ & 397 (16) & $2(6)$ & 601 (18) \\
\hline IIIN & $16(14)$ & $296(12)$ & $6(18)$ & $900(27)$ \\
\hline$\| \mathrm{IIM}$ & $41(35)$ & 899 (37) & $11(34)$ & 480 (14) \\
\hline IV & $18(16)$ & $529(21)$ & $8(24)$ & $895(27)$ \\
\hline v & $9(8)$ & $172(7)$ & $6(18)$ & 351 (11) \\
\hline \multicolumn{5}{|l|}{ Marital status $n(\%)$} \\
\hline Married & $102(88)$ & $2140(87)$ & $19(58)^{* *}$ & $2345(70)$ \\
\hline Widowed & $3(3)$ & $88(4)$ & $12(36)$ & 455 (14) \\
\hline Single & $7(6)$ & 207 (8) & $2(6)$ & 440 (13) \\
\hline Other & $3(3)$ & 27 (1) & $0(0)$ & $82(3)$ \\
\hline \multicolumn{5}{|l|}{ Mean (SD) of CHD risk factor } \\
\hline Systolic BP mm Hg & $152(23)^{* *}$ & $146(22)$ & $166(32)^{* *}$ & $146(24)$ \\
\hline Diastolic BP mm Hg & $87(13)^{*}$ & 85 (13) & $90(16)^{* *}$ & $83(13)$ \\
\hline Cholesterol mmol// & $6.1(1)^{* *}$ & $5.9(1)$ & $7(2)$ & $7(1)$ \\
\hline Body mass index $\mathrm{kg} / \mathrm{m}^{2}$ & $26(3)$ & $26(3)$ & $27(5)^{*}$ & $25(4)$ \\
\hline Forced expiratory volume (1 sec) & $87(24)$ & $89(23)$ & $89(28)$ & $92(23)$ \\
\hline Blood sugar $\mathrm{mmol} / \mathrm{l}$ & $5(1)$ & $5(1)$ & $6(4)^{* *}$ & $5(1)$ \\
\hline \multicolumn{5}{|l|}{ Angina $\mathrm{n}(\%)$} \\
\hline No & $75(65)^{* *}$ & 2063 (84) & $24(73)^{*}$ & $2862(86)$ \\
\hline Yes & $40(35)$ & $399(16)$ & $9(27)$ & 460 (14) \\
\hline \multicolumn{5}{|l|}{ Bronchitis n (\%) } \\
\hline No & $108(94)$ & $2323(94)$ & $32(97)$ & 3211 (97) \\
\hline Yes & $7(6)$ & $139(6)$ & $1(3)$ & $111(3)$ \\
\hline \multicolumn{5}{|l|}{ ECG ischaemia n (\%) } \\
\hline No & $95(83)^{* *}$ & 2246 (91) & $24(73)^{\star *}$ & 3024 (91) \\
\hline Yes & 20 (17) & 216 (9) & $9(27)$ & 298 (9) \\
\hline \multicolumn{5}{|l|}{ Stroke n (\%) } \\
\hline No & $111(96)^{*}$ & 2342 (99) & $33(100)$ & 3295 (99) \\
\hline Yes & $4(4)$ & $30(1)$ & $0(0)$ & 27 (1) \\
\hline \multicolumn{5}{|l|}{ Diabetes n (\%) } \\
\hline No & $111(96)$ & 2430 (99) & $30(91)^{* *}$ & 3293 (99) \\
\hline Yes & $4(4)$ & $32(1)$ & $3(9)$ & $29(1)$ \\
\hline
\end{tabular}

CHD within five years were on average older, and smoked more cigarettes compared with men without five year CHD. In women five year CHD incidence was associated with increasing age, social class IIIM and V, and widowhood. Among male and female respondents who had a CHD event within five years from baseline mean systolic and diastolic blood pressure was higher, mean cholesterol was higher in men, and mean blood sugar and BMI higher in women compared with men and women without five year CHD. In men and women five year CHD was associated with baseline angina, ECG ischaemia, stroke in men, and diabetes in women.

\section{Multivariate analysis of psychological distress and CHD}

At $0-5$ and 5-10 year follow up there were respectively 115 and 78 CHD events in men and 33 and 77 in women (table 3 ). Psychological distress was associated with a $78 \%$ increased risk of five year CHD in men in age adjusted analysis. Adjustment for sociodemographic and CHD risk factors did not attenuate this risk. However, additional adjustment for baseline physical illness attenuated the risk a little but psychological distress was still associated with a $61 \%$ increased risk of incident CHD. There was no association between psychological distress and increased risk of 5-10 year CHD incidence in men. In fact baseline GHQ caseness was associated with a significantly reduced risk in the fully adjusted model. Furthermore, including a psychological distress, physical illness interaction term in the full model showed that the association between psychological distress and CHD did not differ between physically ill and nonphysically ill men $(p=0.46)$. Psychological distress was not associated with $0-5$, or 5-10 year CHD incidence in women either in age or fully adjusted analyses.

To distinguish the risk of incident CHD in men with and without physical illness, further analysis examined the association between CHD incidence in the five years from baseline by baseline psychological distress and physical illness status (table 4). Being GHQ positive but healthy was not associated with five year CHD incidence, either in age or

Table 3 Risk of 0-5, 5-10 year CHD in men and women by baseline psychological distress

\begin{tabular}{|c|c|c|c|c|c|c|c|}
\hline & CHD events & $\mathbf{R R}^{*}$ & $95 \% \mathrm{Cl}$ & RR† & $95 \% \mathrm{Cl}$ & RR $\ddagger$ & $95 \% \mathrm{Cl}$ \\
\hline \multicolumn{8}{|l|}{ Men } \\
\hline 5 & 115 & 1.78 & 1.15 to 2.75 & 1.78 & 1.14 to 2.79 & 1.61 & 1.02 to 2.55 \\
\hline 10 & 78 & 0.43 & 0.17 to 1.06 & 0.42 & 0.17 to 1.04 & 0.39 & 0.15 to 0.98 \\
\hline \multicolumn{8}{|c|}{ Women } \\
\hline 5 & 33 & 1.60 & 0.74 to 3.44 & 1.55 & 0.70 to 3.42 & 1.37 & 0.59 to 3.19 \\
\hline 10 & 77 & 1.11 & 0.64 to 1.93 & 1.05 & 0.60 to 1.85 & 0.76 & 0.42 to 1.36 \\
\hline
\end{tabular}

* Age adjusted; tbaseline sociodemographic (SD), CHD risk factor adjusted; †baseline SD, CHD risk factor and physical illness adjusted. 
Table 4 Risk of five year CHD in men by baseline psychological distress and physical illness status

\begin{tabular}{|c|c|c|c|c|c|c|}
\hline & Number & CHD events & $\mathbf{R R}^{*}$ & $95 \% \mathrm{Cl}$ & RRt & $95 \% \mathrm{Cl}$ \\
\hline GHQ negative and healthy & 1943 & 55 & 1 & 1 & 1 & 1 \\
\hline GHQ positive but healthy & 220 & 5 & 0.77 & 0.31 to 1.91 & 0.74 & 0.29 to 1.87 \\
\hline GHQ negative but ill & 583 & 36 & 2.00 & 1.31 to 3.10 & 2.12 & 1.35 to 3.32 \\
\hline GHQ positive and ill & 185 & 23 & 4.01 & 2.42 to 6.66 & 4.47 & 2.62 to 7.62 \\
\hline
\end{tabular}

fully adjusted analysis. However, being ill but GHQ negative was associated with a twofold increased risk of five year CHD in men in age adjusted analysis and a greater than twofold risk in fully adjusted analysis. Furthermore, being ill and GHQ positive was associated with fourfold increased risk of five year CHD in men in age adjusted analysis and an almost four and half times increased risk after full adjustment.

\section{DISCUSSION}

Psychological distress at baseline was associated with increased five year CHD incidence in men but not women in fully adjusted analysis. However, the association between psychological distress and five year CHD incidence in men was influenced by the presence of baseline physical illness. Psychological distress was associated with a greater five year CHD risk in distressed, physically ill men than non-distressed physically ill men.

This study provides additional support for psychological distress as a significant predictor of CHD in middle aged men, ${ }^{12} 14^{16}$ although not in women. It may be that the meaning of distress is qualitatively different for men than women or that women are readier to seek help for psychological distress from social networks to discuss and relieve its toxic effects. ${ }^{26}$ Psychological distress may lead to poorer health behaviours, in men than women. Also, it may be that the lack of association is attributable to hormonal influences exerting a protective effect against CHD. The association between psychological distress and five year CHD seen in men may be mediated through smoking. ${ }^{27}$ However, this is unlikely as psychological distress has also been found to predict CHD in non-smokers ${ }^{19}$ and adjustment for smoking did not account for the increased risk.

Socioeconomic position may also explain the association between psychological distress and increased risk of CHD. It may be that the stresses of low socioeconomic position are associated with psychological distress, which may lead to the development of CHD. If so then the association between psychological distress and CHD should be less evident among those in higher socioeconomic position. However, Ford et al ${ }^{14}$ found an association between psychological distress and CHD in American medical students-a group unlikely to be from a low socioeconomic background at the time the sample was selected. Thus, the effect of psychological distress on increased CHD risk seen in a sample where increased distress is not associated with low socioeconomic position is unlikely to be attributable to confounding by socioeconomic position, however imperfectly socioeconomic position is measured.

\section{Key points}

- Psychological distress as a determinant of increased short term CHD risk in men independently of physical illness remains unclear.

- The presence of psychological distress among physically ill men doubles CHD risk.

\section{Policy implications}

- There is a need for greater recognition of psychological distress in men with physical illness.

- A need to examine whether psychopharmacological interventions for depressive disorder may reduce CHD risk in men with physical illness.

There is some evidence that depressed people have a poorer CHD risk factor profile. ${ }^{28}$ If CHD risk factors are associated with psychological distress then they might be the link between psychological distress and CHD. However, evidence from this and other studies ${ }^{25} 29-31$ do not support the link between psychological distress and CHD risk factors. Thus, the effect of psychological distress on CHD risk is unlikely to be mediated through CHD risk factors.

What about the role of physical illness? An increased risk of CHD associated with psychological distress was observed in respondents with physical ill health at baseline, for example, angina. It is not entirely clear, however, whether psychological distress is a marker of some underlying chronic physical condition, which increases risk, or a reflection of depressive illness, which despite its transient nature still confers risk. It may be that psychological distress is a consequence of baseline ill health. This may also explain psychological distress's association with five year rather than 10 year CHD risk, with the more vulnerable, physically ill experiencing an event earlier. In fact psychological distress was not associated with an increased five year CHD risk after excluding those who had an event in the first year of follow up suggesting that psychological distress is a consequence of baseline ill health. In this study there were associations between baseline psychological distress and angina, ECG ischaemia, and bronchitis in men and women. Thus the association may be explained by negative affectivity-the tendency of participants reporting symptoms of, for example, angina to also report more symptoms on the GHQ. ${ }^{32}$

Results from some studies have been interpreted to suggest that the association between psychological distress and CHD is explained by adjustment for ill health ${ }^{17}$ whereas other studies still find an increased CHD risk associated with psychological distress even after adjustment for ill health such as cancer, diabetes, stroke, and past CHD. ${ }^{14} 2133$ It is plausible that even after adjustment for ill health especially using self report measures there remains some residual confounding. Furthermore, some studies stratifying their analyses of psychological distress and CHD by physical illness still find an increased CHD risk associated with psychological distress in non-physically ill samples. ${ }^{17}$ In this study though psychological distress was not associated with increased five year CHD risk in healthy men.

Rather than being an independent aetiological agent in CHD risk it may be that psychological distress has a moderating effect on the relation between physical ill health and CHD or is an indicator of the severity of underlying physical illness processes such as inflammation accelerating 
the progression of CHD. Psychological distress may be influencing endothelial dysfunction increasing the rate of progression of CHD in those with existing disease. ${ }^{34}$

If psychological distress is an indicator of underlying disease progression in physically ill men, what might psychological distress be reflecting? Psychological distress may represent fatigue, malaise, or vital exhaustion ${ }^{35}$ associated with the pain and discomfort from physical illnesses like CHD, diabetes, and bronchitis. However, the GHQ measures depressive symptoms and depressive symptoms are not always present within vital exhaustion. ${ }^{36}$ Secondly, the 30 item GHQ was derived from the 60 item GHQ precisely to avoid contamination by physical illness. Thirdly, the GHQ was designed specifically to screen for psychiatric disorder and its scores correlate with depression and clinical psychiatric disorder.

Through what mechanisms might psychological distress increase CHD risk? Psychological distress may be linked to CHD through, changed neuroendocrine function involving the hypothalmic-pituitary-adrenergic axis, blood platelet function, and heart rate variability. ${ }^{37-39}$ If psychological distress is associated with CHD through psychophysiological mechanisms, the short term CHD risk found in this study may be more likely to reflect underlying processes such as susceptibility to arrhythmias, thrombogenesis, or inflammation. Although it is unclear what psychophysiological mechanism may mediate the distress-CHD relation some have suggested that the same psychophysiological mechanism might govern the relation in physically ill and healthy persons. ${ }^{40}$ Others argue that although CHD risk associated with psychological distress is similar in physically ill and healthy people, this does not necessarily imply that the same mechanisms are operating to increase CHD risk in ill and healthy people. ${ }^{41}$ Although a mechanism for the association between psychological distress and CHD risk remains to be identified both pathophysiological and social processes may provide the link between psychological distress and CHD risk.

\section{Limitations}

At baseline $44.7 \%$ of men and $55.3 \%$ of women completed the GHQ. The sample characteristics of participants who did the GHQ differed slightly from those who did not do the GHQ. Participants in Paisley who completed the GHQ compared with Renfrew participants who did not have the opportunity to do the GHQ were more likely to be women than men ( $56 \%$ compared with $44 \%$ ) and non-manual than manual social class (60\% compared with $40 \%$ ). This may have introduced a sampling bias. The sociodemographic characteristics of GHQ respondents have been considered in another paper. ${ }^{22}$ The 30 item GHQ is a screening rather than a diagnostic instrument and requires a second stage clinical interview using standardised psychiatric interview to be certain of identifying clinical psychiatric cases. Without such a second stage procedure it is possible that there is misclassification of cases. In particular, high scorers on the GHQ may include a number of false positives who score highly on the GHQ but do not fulfil the caseness criteria. An analysis without a strategy to compensate for such misclassification, such as this, risks under or over estimating the size of the association between psychological distress and CHD. Additionally, it is probable that psychological distress measured as GHQ caseness, may not all be attributable to mental illness, but may represent false positives indicating physical ill health and disability. Moreover, the 30 item GHQ is a non-specific screening instrument that does not distinguish between different types of common mental disorder, which may have differing associations with CHD risk. Except for the GHQ scoring highly in those with physical illness, these limitations would be likely to reduce the observed risk rather than increase it.

\section{CONCLUSION}

The association of psychological distress with increased short term CHD risk could be a function of baseline physical illness but an association between psychological distress and increased CHD risk in men, independent of physical illness cannot be ruled out. There was no evidence for an association between psychological distress and CHD risk in women. Psychological distress was also prognostically associated with CHD risk. Its presence among physically ill men greatly increased CHD risk. Future research should identify what physiological mechanisms underlie the association between of psychological distress and an increased CHD risk. Additionally, treatment of psychological distress in people who are physically ill may be an effective target for further reducing CHD risk.

\section{Authors' affiliations}

F Rasul, S A Stansfeld, Department of Psychiatry, Barts and the London School of Medicine and Dentistry, Queen Mary, University of London, London, UK

C L Hart, Public Health and Health Policy, Division of Community Based Sciences, University of Glasgow, Glasgow, UK

G Davey Smith, Department of Social Medicine, University of Bristol, Bristol, UK

Funding: the work presented in this article was supported by a grant from the British Heart Foundation (grant no PG/98170) awarded to Professors Stansfeld and Davey Smith, which supported a Research Fellowship for Farhat Rasul.

Conflicts of interest: none declared.

\section{REFERENCES}

1 Wilson PW, D'Agostino RB, Levy DB, et al. Prediction of coronary heart disease using risk factor categories. Circulation 1998;97:1837-47.

2 Braunwald E. Shattuck lecture-cardiovascular medicine at the turn of the millennium: triumphs, concerns, and opportunities. N Engl J Med 1997;337:1360-9.

3 Hemingway H, Marmot M. Psychosocial factors in the aetiology and prognosis of coronary heart disease: systematic review of prospective cohort studies. BMJ 1999;318:1460-7.

4 Vaccarino V. The association between depression and coronary heart disease incidence. Drugs Today 2000;36:715-24.

5 Rozanski A, Blumenthal JA, Kaplan J. Impact of psychological factors on the pathogenesis of cardiovascular disease and implications for therapy. Circulation 1999;99:2192-217.

6 Barrick CB. Sad, glad, or mad hearts? Epidemiological evidence for a causal relationship between mood disorders and coronary artery disease. J Affect Disord 1999:53:193-201.

7 Wielgosz AT, Nolan RP. Biobehavioral factors in the context of ischemic cardiovascular diseases. J Psychosom Res 2000;48:339-45.

8 Ketterer MW, Mahr G, Goldberg AD. Psychological factors affecting a medical condition: ischemic coronary heart disease. J Psychosom Res 2000;48:357-67.

9 Kop WJ. Chronic and acute psychological risk factors for clinical manifestations of coronary artery disease. Psychosom Med 1999;61:476-87.

10 Booth Kewley S, Friedman H. Psychological predictors of heart disease: a quantitative review. Psychol Bull 1987;101:343-62.

11 Wulsin L, Singal, B. Do depressive symptoms increase the risk for the onset of coronary disease? A systematic quantitative review. Psychosom Med 2003;65:201-10

12 Stansfeld SA, Fuhrer R, Shipley MJ, et al. Psychological distress as a risk factor for coronary heart disease in the Whitehall II study. Int J Epidemiol 2002;31:248-55.

13 Ariyo AA, Haan M, Tangen CM, et al. Depressive symptoms and risks of coronary heart disease and mortality in elderly Americans. Circulation 2000; 102:1773-9.

14 Ferketich AK, Schwartzbaum JA, Frid DJ, et al. Depression as an antecedent to heart disease among women and men in the NHANES I study. Arch Intern Med 2000;160:1261-8.

15 Sesso HD, Kawachi I, Vokonas PS. Depression and the risk of coronary heart disease in the normative aging study. Am J Cardiol 1998;82:851-6.

16 Ford DE, Mead LA, et al. Depression is a risk factor for coronary heart disease in men: the precursors study. Arch Intern Med 1998;158:1422-6.

17 Mendes-de-Leon CF, Krumholz HM. Depression and risk of coronary heart disease in elderly men and women: New Haven EPESE, 1982-1991. Established populations for the epidemiologic studies of the elderly. Arch Intern Med 1998;158:2341-8.

18 Barefoot JC, Schroll M. Symptoms of depression, acute myocardial infarction and total mortality in a community sample. Circulation 1996;93:1976-80. 
19 Anda R, Williamson D, Jones D, et al. Depressed affect, hopelessness and the risk of ischaemic heart disease in a cohort of U.S. adults. Epidemiology 1993;4:285-94.

20 Hippisley-Cox J, Fielding K, Pringle M. Depression as a risk factor for ischaemic heart disease in men: population based case-control study. BMJ 1998; 316:1714-18.

21 Everson SA, Goldberg DE, Kaplan GA, et al. Hopelessness and risk of mortality and incidence of myocardial infarction and cancer. Psychosom Med 1996:58:113-21.

22 Rasul F, Stansfeld SA, Davey Smith G, et al. Socio-demographic factors, smoking and common mental disorder in the Renfrew and Paisley (MIDSPAN) study. J Health Psychol 2001;6:149-58.

23 Hawthorne VM, Watt GCM, Hart CL, et al. Cardiorespiratory disease in men and women in urban Scotland: baseline characteristics of the Renfrew/Paisley (MIDSPAN) study population. Scott Med J 1995;40:102-7.

24 Goldberg D. The detection of psychiatric illness by questionnaire. Maudsley monograph no 21. Oxford: Oxford University Press, 1972.

25 Mann AH. Hypertension: psychological aspects and diagnostic impact in a clinical trial. Psychological medicine monograph supplement 5. Cambridge: Cambridge University Press, 1984

26 Grootheest DS, Beekman ATF, Broese van Groenou MI, et al. Sex differences in depression after widowhood. Do men suffer more? Soc Psychiatry Psychiatr Epidemiol 1999;34:391-8.

27 Anda RF, Williamson DF, Escobedo LG, et al. Depression and the dynamics of smoking. A national perspective. JAMA 1990;264:1541-5.

28 Lesperance F, Frasure-Smith N, Talajic M. Major depression before and after myocardial infarction: its nature and consequences. Psychosom Med 1996:58:99-110.

29 Wardle J. Cholesterol and psychological well being. J Psychosom Res 1994;39:549-62.
30 Simonsick EM, Wallace RB, Blazer DG et al. Depressive symptomatology and hypertension associated morbidity and mortality in older adults. Psychosom Med 1995;57:427-35.

31 Roberts RE, Kaplan GA, Shema SJ, et al. Are the obese at greater risk for depression? Am J Epidemiol 2000;152:163-70.

32 Macleod J, Davey Smith G, Heslop P, et al. Psychological stress and cardiovascular disease: empirical demonstration of bias in a prospective observational study of Scottish men. BMJ 2002;324:1247-51.

33 Penninx BWJH, Guralnik JM, Mendes-de-Leon CF, et al. Cardiovascular events and mortality in newly and chronically depressed persons $>70$ years of age. Am J Cardiol 1998;81:988-94.

34 Rajagopalan S, Brook R, Rubenfire $M$, et al. Abnormal brachial artery flowmediated vasodilation in young adults with major depression. Am J Cardiol 2001;88:196-8.

35 Appels A. Exhausted subjects, exhausted systems. Acta Physiol Scand 1997;640: 153-4

36 Van Diest R, Appels A. Vital exhaustion and depression: a conceptual study. J Psychosom Res 1991;35:535-44

37 Musselman DL, Evans DL, Nemeroff CB. The relationship of depression to cardiovascular disease. Arch Gen Psychiatry 1998;55:580-92.

38 Anfossi G, Trovati M. Role of catecholamines in platelet function: pathophysiological and clinical significance. Eur J Clin Invest 1996:26:353-70

39 Miyawaki E, Salzman C. Autonomic nervous system tests in psychiatry: implications and potential uses of heart rate variability. Integr Psychiatry $1991 ; 7: 21-8$

40 Penninx BWJH, Beekman ATF, Honig A, et al. Depression and cardiac mortality. Results from a community-based longitudinal study. Arch Gen Psychiatry 2001;58:221-7.

41 Carney RM, Freedland KE, Jaffe AS. Depression as a risk factor for coronary heart disease mortality. Arch Gen Psychiatry 2001;58:229-30. 